\title{
COVID-19: a espiritualidade harmonizando saúde mental e física
}

\section{COVID-19: spirituality harmonizing mental and physical health}

\author{
Márden Cardoso Miranda Hott ${ }^{1}$ [10
}

1. Docente do Programa de Pós-Graduação em Educadores da Saúde pela Universidade Federal de Minas Gerais (UFMG), Belo Horizonte, MG, Brasil.

\section{Resumo}

\begin{abstract}
Introdução: perante o COVID-19, que limita os contornos do existir humano, a espiritualidade, ao compor diferentes extensões do cuidar em saúde, torna-se elemento imprescindível para nutrir o ensejo de lutar pela sobrevivência. Método: comunicação breve, atentando para questões emocionais que envolvem a pandemia. Resultado e conclusão: embora espiritualizar seja processo personalizado, exercício permanente e não haja senda específica para desenvolvêla, é possível principiar pelo autoconhecimento. Este pode potencializar o ser humano com a capacidade de se ver, proporcionando o desenvolvimento de ações estoicas diante de situações difíceis, dotando-o de força interior para atingir o equilíbrio entre mente, corpo e alma.
\end{abstract}

Palavras-chave: Covid-19. Espiritualidade. Fé. Saúde Mental. Saúde Física.

\begin{abstract}
Introduction: Before COVID-19, which limits the contours of human existence, spirituality, by composing different extensions of health care, becomes an indispensable element to nourish the opportunity to fight for survival. Method: Brief communication focusing on emotional issues involving the pandemic. Result and conclusion: Although spiritualizing is a personalized process, permanent exercise and there is no specific path to develop it, it is possible to begin with self-knowledge. This can enhance the human being with the ability to see himself/herself, providing the development of stoic actions in the face of difficult situations, endowing them with inner strength to achieve the balance between mind, body and soul.
\end{abstract}

Keywords: Covid-19. Spirituality. Faith. Mental Health. Physicalhealth.

Perante a surpreendente pandemia do COVID-19, que limita os contornos do existir humano, a espiritualidade, ao compor diferentes extensões do cuidar em saúde, pode-se tornar elemento imprescindível para nutrir o ensejo de lutar pela sobrevivência. No cenário do "Novo Coronavírus", o despertar espiritual espelha a vulnerabilidade; porém, em contraponto, volta-se para esforços que acenam para a positividade e empatia, favorecendo a saúde física e emocional da sociedade que busca agir e reagir em comunhão. No entanto, a ameaça da infecção é legítima, e os efeitos têm atingido a população em variados aspectos, tanto pessoais, quanto comunitários, implicando uma condição alarmante de saúde pública.

A Conferência Internacional sobre Cuidados Primários de Saúde (que ocorreu na arcaica União Soviética em 1978) alterou a visão sobre o binômio "saúde e doença", agregando três dimensões: física, social e mental, estando esta última atrelada à espiritualidade ${ }^{1}$. Posteriormente, o conceito foi adotado pela Organização Mundial da Saúde ao considerar que o enlevo espiritual é uma vertente da concepção de ser e estar saudável em conformidade com os aspectos corporais, psíquicos e coletivos ${ }^{2}$. Portanto, a saúde espiritual se constitui como dimensão fundamental que define como as pessoas harmonizam as relações que estabelecem consigo mesmo, com o ambiente, com alguém ou com algo para além do humano³.

Entende-se por "espiritualidade" o atributo inato da essência humana que promove bem-estar e dá um novo sentido à vida, o que é diferente de "religiosidade", que pode ser compreendida como a manifestação da adoção de valores, crenças e rituais que respondem às perguntas basilares sobre o viver e o morrer ${ }^{4}$, apesar das variadas versões conceituais que confundem os termos e, com isso, ainda não atingiram senso comum. No entanto, é consensual que a espiritualidade promove a introspecção e potencializa o ser humano com a capacidade de se ver, proporcionando o desenvolvimento de ações estoicas diante de situações complexas e difíceis, dotando o indivíduo de força interior para atingir o equilíbrio de mente, do corpo e da alma.

Entre saúde e espiritualidade, o diálogo tem ocupado espaço progressivamente considerável, distanciando as discrepâncias e acertando os descompassos. Isso se dá pela relevância da (res)significação do viver, adoecer, sobreviver ou fenecer. Essas questões existenciais (que podem implicar crises) têm sido reconhecidas por pesquisadores pares ou díspares, associando na interdisciplinaridade diferentes prismas para um mesmo foco. Nesse recente cenário, a objetividade vem abrindo espaço 
para questões subjetivas que sempre imperaram na sociedade humana, mas que foram relegadas há tempos pela ausência de materialidade sobre a questão.

Estudos apontam que tanto a pandemia, quanto as medidas preconizadas para sua contenção têm impactado na saúde mental da população global, elevando o risco para ocorrência de ansiedade, estresse e depressão ${ }^{5}$. As pessoas vivenciam alterações drásticas em seus cotidianos e necessitam lidar com a imprevisibilidade futura ${ }^{6}$, sendo que outras foram acometidas pela infecção ou perderam entes do seu contexto socioafetivo em função da doença ${ }^{7}$. No entanto, mesmo que não haja prejuízo direto, as pessoas podem desenvolver aflições e sensibilidades por empatia aos afetados ${ }^{8}$.

Contudo, para determinados indivíduos que experienciam sofrimentos pessoais ou alheios, a consciência acerca da necessidade de espiritualizar-se pode favorecer o entendimento e a elaboração saudável dos fatos vivenciados. Assim, a espiritualidade pode dar um impulso na qualidade de vida, sendo a fé - o ingrediente que melhor a traduz - o contribuinte para a otimização das manifestações físicas e psicológicas, pois afirma a existência do ser humano em sua multiplicidade, suplantando o zelar exclusivamente biológico ${ }^{9}$.

Entre as necessidades humanas básicas abarcadas por Maslow, a espiritualidade é imprescindível para que a pessoa possa organizar-se de forma coerente e segura no universo em que habita. Para tal, é preciso que ela encontre um pilar que direcione e justifique suas ações que, por vezes, provêm do âmbito divinal ${ }^{10}$. A fé, sendo previdência das futuras possibilidades, faz sentido somente para quem crê (em algo), por ser uma experiência individual e inalienável em todo homem ${ }^{11}$. Esta se desenha como elemento estratégico para enfrentar as adversidades. Por outro lado, perdê-la pode ser um desencadeador da desesperança, tornando a lida com o forçoso "novo normal" um inconveniente e resistente meio para alcançar a (re)adaptação.

Na condição de negatividade, os valores humanos e as expressões do sagrado, por vezes, são desprezados, e sentimentos angustiantes vão ocupando o seu lugar. É nesta situação que o cuidar de si e do outro deve ganhar espaço mais abrangente para que se possa sair do looping emocional que movimenta a mente e paralisa a alma pelo efeito nocivo que gera. Assim, o círculo vicioso da angústia precisa ser interrompido para se ancorar no que possa ser salutar, como o desenvolvimento da resiliência.

A angústia é definida como um sinal antecipado crucial e de fundo biológico, acarretado para alertar o organismo de um perigo que ameaça o seu equilíbrio; portanto, é sentida como aumento na tensão corporal e mental que coloca o indivíduo em estado de vigilância interna ${ }^{12}$. A resiliência é entendida como a capacidade humana que mobiliza o desenvolver-se e o projetar-se para o porvir em face das situações difíceis da vida, envidando esforços para lidar, superar e modificar a ótica a qual se prende, mesmo diante de um evento adverso inevitável ${ }^{13}$. Percebe-se que não há antagonismo na acepção, mas que precedendo à angústia, é possível avançar, neutralizando-a mediante a resiliência conquistada por meio da espiritualização.

Embora o espiritualizar seja um processo profundamente personalizado e um exercício permanente, e que não haja uma senda específica ou universal para encontrá-la e/ou desenvolvê-la, é possível principiar por meio da motivação em buscar o autoconhecimento ou o autoexame. A cura para os males da alma encontra-se no ser, mesmo que recursos alternativos sejam substanciais elementos de apoio que podem tornar-se referenciais significativos para a instrução, a reflexão e abstração.

Assim, em meio à paralisação global imposta pelo COVID-19, esta pode ser uma oportunidade para ativar o potencial íntimo e, em vez do exaurir em aflições, captar do caos interior e exterior o que apenas "parece" ser improvável, a promoção da salubridade psíquica (expendendo a espiritualidade) como adjuvante da saúde física, que também urge em ser balizada por medidas sanitárias conscienciosas e eficazes.

\section{REFERÊNCIAS}

1- Diniz JPS. O essencial ao invisível a tua fé te curou: estudo sociológico sobre os processos de cura [monografia]. Campina Grande (PB): Universidade Federal de Campina Grande; 2019.

2- Fleck MP, Borges ZN, Bolognesi G, Rocha NS. Desenvolvimento do WHOQOL, módulo espiritualidade, religiosidade e crenças pessoais. Rev. Saúde Pública[Internet]. 2003 Ago [acesso 20200 Jul 20]; 37(4): 446-455. Disponível em: http://www.scielo.br/scielo.php?script=sci_arttext\&pid=S003489102003000400009\&Ing=en. doi: http://dx.doi.org/10.1590/S003489102003000400009 .

3- Fisher J. Understanding and assessing spiritual health. International Handbook of Education for Spirituality, Care and Well-being. New York: Springer; 2009.

4- Cavalheiro CMF, Falcke D. Espiritualidade na formação acadêmica em psicologia no Rio Grande do Sul. Estud. psicol (Campinas). [Internet]. 2014 [acesso em 2020 Jul 20]; 31(1); 35-44. Disponível em: https://www.scielo.br/ scielo.php?script=sci_arttext\&pid=S0103-166X2014000100004\&lng=pt\&tlng= pt. doi: https://dx.doi.org/10.1590/0103-166X2014000100004.
5- Wang C, Pan R, Wan X, Tan Y, Xu L, Ho CS. Immediate psychological responses and associated factors during the initial stage of the 2019 coronavirus disease (COVID-19) epidemicamongthe general population in china. Int J Environ Res Public Health.2020 Mar 6;17(5):1729. doi: 10.3390/ijerph17051729. PubMed PMID: 32155789.

6- Weaver MS, Wiener L. Applying palliative care principles to communicate with children about COVID-19. J Pain Symptom Manage. 2020 Jul; 60(1): e8e11. doi: https://doi.org/10.1016/j.jpainsymman.2020.03.020. PubMedPMID: 32240751.

7- Arango C. Lessons learned from the coronavirus health crisis in Madrid, Spain: How COVID-19 has changed our lives in the last 2 weeks. Biol Psychiatry. [Internet]. 2020 Out [acesso 2020 Jul 19]; 88(7): e33-e34. Disponível em: https://www.biologicalpsychiatryjournal.com/article/S0006-3223(20)31493-1/ pdf. doi: 10.1016/j.biopsych.2020.04.003.

8- Weir K. Grief and COVID-19: mourning our bygone lives [Internet]. American Psychological Association; 2020 Abr [acesso 2020 Jul 18]. Disponível em: 
https://www.apa.org/news/apa/2020/04/grief-covid-19.

9- Bovero A, Leombruni P, Miniotti M, Rocca G, Torta R. Spirituality, quality of life, psychological adjustment in terminal cancer patients in hospice. Eur J CancerCare. 2016Nov; 25(6):961-969. doi: 10.1111/ecc.12360. PubMed PMID: 26215314.

10- Maslow AH. Uma teoria da motivação humana de 1943 [Internet]. 2019 [acesso 2020 Jul 21]. 18p. Disponível em: https://www.marciokarsten.pro. br/wp-content/uploads/2019/11/Uma-teoria-da-motiva\%c3\%a7\%c3\%a3ohumana.pdf.

11- Leão EC. Crença, fé e teoria. Scintilla. [Internet]. 2017 Jan-Jun [acesso 2020
Jul 18];14(1):29-38. Disponível em: https://scintilla.saoboaventura.edu.br/ scintilla/article/view/39/33.

12- Freud S. Rascunho E: como se origina a angústia. In Freud S. Obras psicológicas completas de Sigmund Freud: edição standard brasileira. Rio de Janeiro: Imago; 1996. v. 1.

13- Brandão JM, Mahfoud M, Gianordoli-Nascimento IF. A construção do conceito de resiliência em psicologia: discutindo as origens. Paidéia [Internet]. 2011 [acesso 2020 Jul 20]; 21(49): 263-271. Disponível em: http://www.scielo. $\mathrm{br} /$ scielo.php?script=sci_arttext\&pid=S0103-863X2011000200014\&lng=en\&nr m=iso. doi: https://doi.org/10.1590/S0103-863X2011000200014.

\section{Como citar este artigo/How to cite this article:}

Hott MCM, COVID-19: a espiritualidade harmonizando saúde mental e física. J Health Biol Sci. 2020 J; 8(1):1-3. 